\title{
How to use fuzzy set theory to select a library manager
}

\author{
Murat Yilmaz' \\ Department of Information and Documentation Management, Faculty of Letters, \\ Istanbul Universitesi,Bilgi ve Belge, Yonetimi Bolumu, Edibiyat Fakultesi \\ Ordu Cad. No: 196, 34459, Laleli, Istanbul, Turkiye \\ myz@istanbul.edu.tr
}

Received: I 4th May 2006

Accepted: $25^{\text {th }}$ July 2006

\begin{abstract}
The purpose of this paper is to demonstrate how to select a library manager using fuzzy set theory. For this purpose, we first designate the set of professional criteria, which a library manager must meet, as $\left(a_{1}, a_{2}, a_{3}, \ldots, a_{n}\right)$. Secondly, we assign the weights, $\left(u_{j}\right)$, representing the relative importance of each criterion, which are fuzzy numbers in the unit interval $[0,1]$, to these professional criteria. Thirdly, we determine the extent to which the library manager candidates satisfy these criteria as $\left(b_{j}\right)$, which are also fuzzy numbers in the unit interval $[0, I]$. Fourthly, we combine the candidates' degrees of professional ability using an aggregator known as the OWA operator. As a result of this combination, the most desirable candidate is the one with the highest score, which is a fuzzy number in the unit interval $[0, I]$.
\end{abstract}

Keywords: Fuzzy set theory, Library manager, Decision-making, OWA operator

\section{Introduction}

Library managers make and implement important decisions regarding the future of their libraries. Although candidates for such positions therefore need to possess personal qualities such as fairness, flexibility, diplomacy, patience, and commitment, etc., the professional skills and qualifications of a candidate may be the important selection criteria. Table I shows a typical set of such professional criteria.

Table I Necessary professional criteria for a library manager

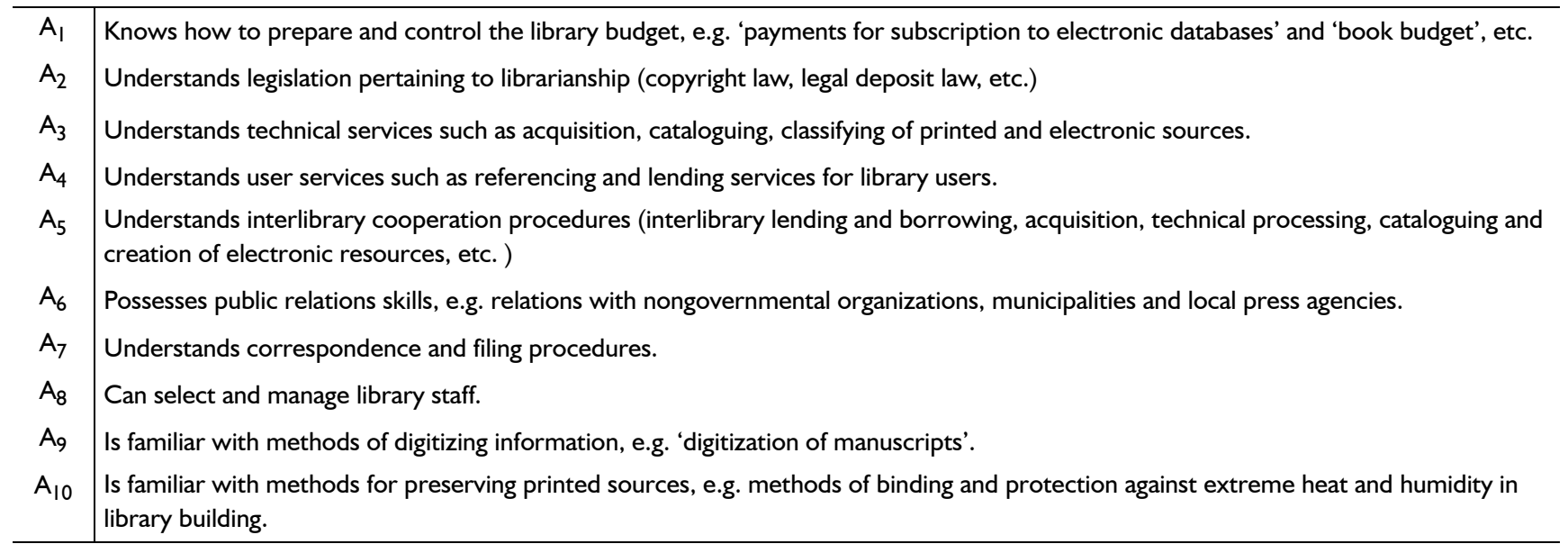

The criteria are not exhaustive but used to exemplify. Clearly these professional criteria differ in degree of importance. In order to choose the most desirable library manager candidate according to these criteria, we need to quantify the 'the importance of the criteria' and 'the extent to which the library manager candidates satisfy them'. The best tool for this is fuzzy set theory, for it has the power to represent them both as linguistic values (or fuzzy labels) used in spoken language and as fuzzy numbers in the unit interval $[\mathbf{0 , 1}]$.

Library and information science has been developing with the aid of the mathematical tools such as 'fuzzy set theory' used in applied sciences. The purpose of this paper is to demonstrate how to select a library manager using the fuzzy set theory as a mathematical tool. First we need to briefly look at the classic set theory to appreciate the need for fuzzy set theory. We will then explain the application of fuzzy set theory to decision making, emphasizing the roles of the OWA operator, linguistic quantifier and linguistic values. Finally, we will use an example to illustrate how to select a library manager using this theory.

I. Murat Yilmaz $(\mathrm{PhD})$ is a lecturer in the Department of Information and Documentation Management, Faculty of Letters, Istanbul University, Turkey 


\section{Classic Set Theory}

Set theory invented by George Canton in the latter part of 19th century deals with sets and their characteristics. The term set can be defined as a collection or class of objects. If $A$ is a set and the object $x$ is a member (or an element) of the set $A$, then we use the notation $\mathbf{x} \in \mathbf{A}$. If an object $y$ is not a member (or an element) of the set $A$, then we use the notation $\mathbf{y} \notin \mathbf{A}$. In the classic set theory, an object either belongs to a given set or does not (Schaefen and Schaefen 1979: 278). Membership in classic set theory is as clear as 'black' and 'white', because a classic set has well-defined set boundaries (Hood and Wilson 2002: 395; Munakata and Jani 1994: 72; Treadwell 1995: 92). However, such sets have limited applications: For example, let us examine the set of animals (A). Elements such as dog, cat, horse and bird, etc. are clearly members of this set $(I, \mathbf{x} \in \mathbf{A})$ and elements such as rock, fluid and plant etc. are clearly not members $(\mathbf{0}, \mathbf{x} \notin \mathbf{A})$. But classic set theory cannot be applied to situations where membership is unclear, e.g. as to whether elements such as starfish and bacteria are members of the set of animals (Zadeh 1965: 338). Nor can it be applied to sets described by linguistic statements such as thick books and short tables. In the middle of the 1960s, Lotfi Zadeh developed fuzzy set theory to resolve the problem of membership. In fuzzy sets the membership of an object $x$ of a set $A$ is not only I (x $\in \mathbf{A})$ or $\mathbf{0}(\mathbf{x} \notin \mathbf{A})$ but rather a degree of membership being a number between 0 and I [ $\left.0 \leq \boldsymbol{\mu}_{\mathbf{A}}(\chi) \leq 1\right]$ (Arfi 2005: 25; Roth and Mervis 1983: 509).

\section{Fuzzy Set Theory}

In a fuzzy set, the membership degrees of the elements are assigned by a membership function having a value between 0 and $\mathrm{I}$, and such a set is characterized by this function (Dualibe 2003: 16). We can also define fuzzy linguistic terms such as young, thick and short by the membership function $(\mu(x))$ (Lee and Yeung and Tsang 2002: 767). But we subjectively state this definition as a decision maker. In this context, the membership function of a fuzzy set is a useful tool in modelling a decision maker's preference profiles (Dae-Young 2003: 3I). As an example, let us examine the vague definition young (Y) subjectively.

$\mathrm{Y}=\left\{\chi, \mu_{\gamma}(\chi)\right\}=\{(22,0.2),(24,0.4),(26,0.6),(28,0.8),(30,1),(32,0.8),(34,0.6),(36,0.4),(38,0.2)\}$

As a library manager candidate, a 28 -year-old person here is symbolized as $(28,0.8)$, meaning that this person is an $80 \%$ member of this set. Only a 30 -year-old person is a $100 \%$ member of this set. In library and information science, which is closer to social sciences, this theory is a useful tool for decision-making problems ${ }^{2}$ [See Ref. (Turner and O'Brien 1984: 228-234)]

\section{Fuzzy set theory and decision-making}

Decision-making consists of selecting the best alternative from a given alternative set (Xu 2004: 20). In decision-making problems, if the decision criteria differ in degree of importance, the decision maker will have more difficulty in selecting the best alternative. In order to overcome this difficulty, Bellman and Zadeh suggested that each of the criteria would be represented as a fuzzy subset over the set of alternatives. (Riberio and Pereira 2003: 330; Yager 1999: 188). In this context, all the fuzzy subsets may be regarded as the different pieces of information that consist of 'weights representing degree of importance of the professional criteria' and 'the weights associated with the extent to which the alternatives/ candidates meet each criterion'. To select the best candidate, all this information is combined by means of an aggregator known as the OWA (Ordered Weighted Averaging) operator.

The OWA operator, which combines different pieces of information by means of their weights, was introduced by Yager in 1988 (Xu 2005: 843; Xu, 2004: 20; Majlender 2005: 340; Ben-Arieh 2005: 293; Wang and Parkan 2005: 21; Smolikova and Wachowiak 2002: 24). Its two essential features are 'reordering the arguments (or relevant criteria)' and 'the set of weights'. 'Reordering' involves ordering the arguments/criteria in descending order, based upon their values (Pelaez and Dona 2003a: 470; Filev and Yager 2003: 672). In the OWA operator, 'the set of weights' must meet the following two conditions: (Yager 2006: 579; Yager 2004a: I78; Yager 2004b: 1952; Yager 2002: 690)

Condition I: $\quad \mathrm{w}_{\mathrm{j}} \in[0, \mathrm{I}] \quad$ Condition $2: \quad \sum_{j=1}^{n} w_{j}=1$

2. Fuzzy set theory is also a suitable tool for 'information retrieval', which deals with retrieving those documents which meet the needs of library users. In information retrieval systems, if all documents are a universal set, then those documents related to an index term are a subset of it. Fuzzy information retrieval systems work as follows. An indexer assigns a weight of value between 0 and I, expressing the degree to which the index terms are associated with documents. That is indexer will assign a value of I to a document directly related to the index term, and 0.I to one minimally related (Hood and Wilson 2002: 397; Bookstein 1985: I2I). Database users combine the index terms with Boolean operators (and, or, not) to retrieve the relevant documents. 
If these two conditions are met, we can define OWA operator as

$O W A_{w}\left(a_{1}, a_{2}, a_{3}, a_{n}\right)=\sum_{j=1}^{n} w_{j} \cdot b_{j}$

[Formula I]

$\left(b_{j}\right.$ in the formula is the $j^{\text {th }}$ largest element of the collection of aggregated criteria $\left.a_{1}, a_{2}, a_{3}, \ldots, a_{n}\right)$

The OWA operator plays an important role in modelling the linguistic (or fuzzy) quantifiers (Kacprzyk and Zadrozyn 2002: I28I). That is to say, it provides for linguistic statements such as 'most criteria must be met' to be expressed in a mathematical formula (Yager 1999: I88). In classical (or binary) logic, there are two quantifiers: 'at least one ( $\exists$ )' and 'all $(\forall)$ ' used to determine a quantifier to solve a decision-making problem. So, classical logic allows a decision maker to stipulate either 'at least one criterion must be met' or 'all criteria must be met'. However, for expressing such quantifiers as most, many, few or half in spoken language, Zadeh suggested using the linguistic (or fuzzy) quantifier $\mathbf{Q}$ represented by a fuzzy subset $\mathbf{Q}(\mathbf{r})$ over $[\mathbf{0}, \mathbf{I}]$, where $\mathbf{Q}(\mathbf{r})$ indicates the degree to which the portion of objects $\mathbf{r}$ satisfies the concept indicated by the quantifier $\mathbf{Q}$ (Yager, 1993). If $\mathbf{Q}(\mathbf{r})$ is $\mathbf{I}$, the concept is fully satisfied, and if a $\mathbf{Q}(\mathbf{r})$ is $\mathbf{0}$, the concept is not satisfied at all. Thus using linguistic quantifiers we can model the proportion of the criteria, which the library manager candidates satisfy". The question which then arises is 'How can we determine the extent to which a library manager candidate satisfies a professional criterion?' This we answer by means of linguistic values (or fuzzy labels).

In certain situations, we use linguistic values instead of numbers in order to evaluate information (Pelaez and Dona 2003b: 810). For example, let us evaluate a 'reading room'. We use some linguistic values such as 'good', 'very good' or 'bad' for the comfort of the reading room. Decision makers can use linguistic values such as 'important' or 'unimportant' as fuzzy numbers over the unit interval [0,I] (Garcia-Lapressa and Louis 2006: 356-358; Sheng-Lin and Reay-Chen and Shih-Yuan 2006: 350-35I) to assign weights to the professional criteria and 'good', 'very good', 'very bad' also over [0,I], to assign the candidates a score for each criterion. But the weights must be explicitly defined and known by the assessing actors beforehand. Posterior assignment of scores arbitrarily is not allowed for statistical reasons.

\section{An illustrative example of the selection of a library manager}

Suppose that we have three library manager candidates $(X, Y, Z)$ and the ten professional criteria as per Table I. The first stage of the process involves assigning weights to those criteria, which are not of equal importance. By means of the linguistic values (or fuzzy labels), we can represent the weights of the criteria as real numbers in the unit interval [0,I]. Table 2 shows possible linguistic values of the weights and Table 3 the consequent numerical value of the weight allocated to each criterion $\left(u_{j}\right)$.

Table 2 Linguistic values representing the degree of importance of each professional criterion

\begin{tabular}{lc}
\hline \multicolumn{1}{c}{ Linguistic values } & $\begin{array}{c}\text { Numerical } \\
\text { weights }\end{array}$ \\
\hline Extremely important & $\mathrm{I}, 0$ \\
Very very important & 0,9 \\
Very important & 0,8 \\
Important & 0,7 \\
More or less important & 0,6 \\
Fair & 0,5 \\
More or less unimportant & 0,4 \\
Unimportant & 0,3 \\
Very very unimportant & 0,2 \\
Very unimportant & 0,1 \\
Extremely unimportant & 0,0 \\
\hline
\end{tabular}

Table 3 Weights representing the degree of importance of all professional criteria

\begin{tabular}{cc}
\hline Criteria & $\begin{array}{c}\text { Numerical } \\
\text { weights }\end{array}$ \\
\hline$A_{1}$ & 1,0 \\
$A_{2}$ & 0,9 \\
$A_{3}$ & 0,6 \\
$A_{4}$ & 0,6 \\
$A_{5}$ & 0,8 \\
$A_{6}$ & 0,7 \\
$A_{7}$ & 0,4 \\
$A_{8}$ & 0,8 \\
$A_{9}$ & 0,7 \\
$A_{10}$ & 0,7 \\
\hline
\end{tabular}

3.In practice a library manager candidate may not completely meet all of the professional criteria. In this situation, a decision maker can select a candidate meeting most of the criteria. Most is represented by the linguistic quantifier $Q(r)=r^{2}$. 
We see why the weights in Table 3 are different by considering for example the criteria $A_{1}$ and $A_{7}$. $A_{1}(K n o w s$ how to prepare and control the library budget) is extremely important for a library manager and $A_{7}$ (Understands correspondence and filing procedures) is not usually important. The weights assigned to the criteria may also change according to the type of library. The second stage of the process involves assigning the candidate a score for each criterion. Table 4 shows the consequent numerical values of the scores assigned to each candidate for each criterion. ${ }^{4}$

Table 4 Scores assigned to each candidate for each criterion

\begin{tabular}{llllll}
\multicolumn{2}{c}{ The candidate $\mathrm{X}:$} & \multicolumn{2}{c}{ The candidate $\mathrm{Y}:$} & \multicolumn{2}{c}{ The candidate $\mathrm{Z}:$} \\
\hline $\mathrm{A}_{1}(\mathrm{x})=$ & 0,8 & $\mathrm{~A}_{1}(\mathrm{y})=$ & 0,7 & $\mathrm{~A}_{\mathrm{I}}(\mathrm{z})=$ & $\mathrm{I}, 0$ \\
$\mathrm{~A}_{2}(\mathrm{x})=$ & 0,9 & $\mathrm{~A}_{2}(\mathrm{y})=$ & 0,6 & $\mathrm{~A}_{2}(\mathrm{z})=$ & 0,9 \\
$\mathrm{~A}_{3}(\mathrm{x})=$ & $\mathrm{I}, 0$ & $\mathrm{~A}_{3}(\mathrm{y})=$ & 0,4 & $\mathrm{~A}_{3}(\mathrm{z})=$ & 0,8 \\
$\mathrm{~A}_{4}(\mathrm{x})=$ & 0,4 & $\mathrm{~A}_{4}(\mathrm{y})=$ & 0,8 & $\mathrm{~A}_{4}(\mathrm{z})=$ & 0,7 \\
$\mathrm{~A}_{5}(\mathrm{x})=$ & 0,5 & $\mathrm{~A}_{5}(\mathrm{y})=$ & 0,9 & $\mathrm{~A}_{5}(\mathrm{z})=$ & 0,8 \\
$\mathrm{~A}_{6}(\mathrm{x})=$ & 0,5 & $\mathrm{~A}_{6}(\mathrm{y})=$ & 0,8 & $\mathrm{~A}_{6}(\mathrm{z})=$ & 0,8 \\
$\mathrm{~A}_{7}(\mathrm{x})=$ & 0,9 & $\mathrm{~A}_{7}(\mathrm{y})=$ & 0,5 & $\mathrm{~A}_{7}(\mathrm{z})=$ & 0,5 \\
$\mathrm{~A}_{8}(\mathrm{x})=$ & 0,7 & $\mathrm{~A}_{8}(\mathrm{y})=$ & 0,8 & $\mathrm{~A}_{8}(\mathrm{z})=$ & 0,8 \\
$\mathrm{~A}_{9}(\mathrm{x})=$ & 0,7 & $\mathrm{~A}_{9}(\mathrm{y})=$ & 0,7 & $\mathrm{~A}_{9}(\mathrm{z})=$ & 0,7 \\
$\mathrm{~A}_{10}(\mathrm{x})=$ & 0,7 & $\mathrm{~A}_{10}(\mathrm{y})=$ & 0,9 & $\mathrm{~A}_{10}(\mathrm{z})=$ & 0,7 \\
\hline
\end{tabular}

The last stage of our process involves combining the weight for each of the criteria with the corresponding obtained scores, per person, by means of the OWA operator, the process being as follows (Yager and Kelman 1999: 407; Yager 1996: 125-127):

Step 1: Order the scores in descending order and enter them in the $b_{j}$ column. (See Table 5)

Step 2: Order the weights of the criteria and enter them in the $u_{j}$ column. (See Table 5)

Step 3: Calculate the values of OWA weights $\left(w_{j}\right)$ using the following formula:

$w_{j}(\chi)=Q\left(s_{j}\right)^{2}-Q\left(s_{j_{-1}}\right)^{2}$

[Formula 2]

$\left(\mathrm{S}_{\mathrm{j}-1}\right.$ : The score of the person's criterion according to step 2$)$

$s_{j}=\frac{1}{T} \sum_{k=1}^{J} u_{k}$

[Formula 3]

$T=\sum_{k=1}^{n} u_{k}$

[Formula 4]

$\left(T=u_{j}:\right.$ the sum of scores: 7,2$)$

Step 4: Calculate the decision function $\mathbf{D}(\mathbf{x})$ for each candidate using the following formula:

$D_{(\chi)}=\sum_{i=1}^{n} w_{i}(\chi) \cdot b_{i}$

[Formula 5]

4.The scores can be assigned to each candidate for each criterion with the aid of traditional selection methods such as oral and written examinations. So, with the help of fuzzy set theory, the traditional selection methods may have a strong influence over the process of decision-making. 
We can see the score for each library manager candidate calculated by means of the OWA operator in Table 5.

Table 5 The scores of each library manager candidate $(X, Y, Z)$

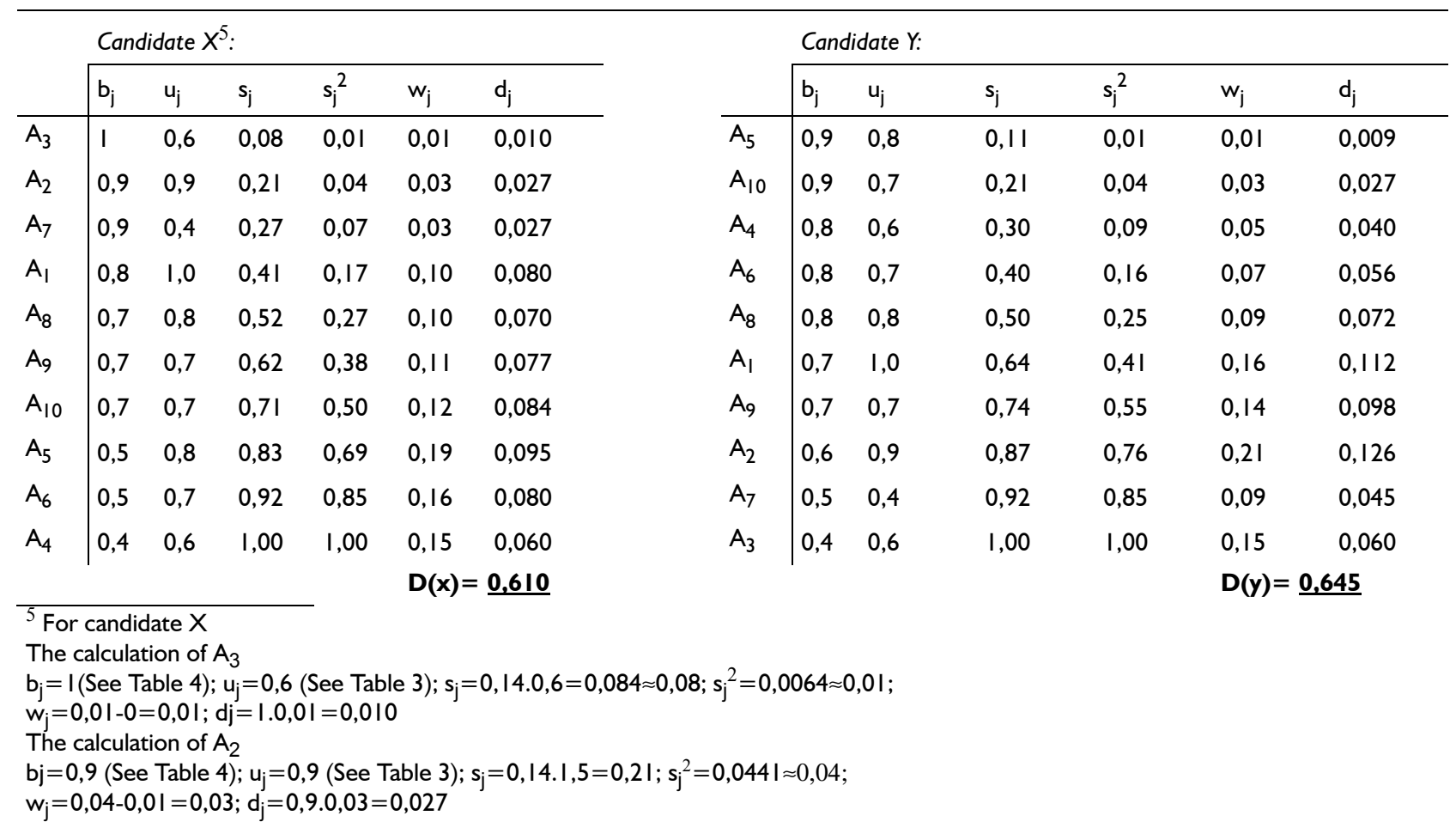

\begin{tabular}{l|llllll}
\multicolumn{7}{c}{ Candidate $\mathrm{Z:}$} \\
\cline { 2 - 7 } & $\mathrm{b}_{\mathrm{j}}$ & $\mathrm{u}_{\mathrm{j}}$ & $\mathrm{s}_{\mathrm{j}}$ & $\mathrm{s}_{\mathrm{j}}^{2}$ & $\mathrm{w}_{\mathrm{j}}$ & $\mathrm{d}_{\mathrm{j}}$ \\
\hline $\mathrm{A}_{\mathrm{I}}$ & $\mathrm{I}, 0$ & $\mathrm{I}, 0$ & 0,14 & 0,02 & 0,02 & 0,020 \\
$\mathrm{~A}_{2}$ & 0,9 & 0,9 & 0,27 & 0,07 & 0,05 & 0,045 \\
$\mathrm{~A}_{3}$ & 0,8 & 0,6 & 0,35 & 0,12 & 0,05 & 0,040 \\
$\mathrm{~A}_{5}$ & 0,8 & 0,8 & 0,46 & 0,21 & 0,09 & 0,072 \\
$\mathrm{~A}_{6}$ & 0,8 & 0,7 & 0,56 & 0,31 & 0,10 & 0,080 \\
$\mathrm{~A}_{8}$ & 0,8 & 0,8 & 0,67 & 0,45 & 0,14 & 0,112 \\
$\mathrm{~A}_{4}$ & 0,7 & 0,6 & 0,76 & 0,58 & 0,13 & 0,091 \\
$\mathrm{~A}_{9}$ & 0,7 & 0,7 & 0,85 & 0,72 & 0,14 & 0,098 \\
$\mathrm{~A}_{10}$ & 0,7 & 0,7 & 0,95 & 0,90 & 0,18 & 0,126 \\
$\mathrm{~A}_{7}$ & 0,5 & 0,4 & $\mathrm{I}, 00$ & $\mathrm{I}, 00$ & 0,10 & 0,050 \\
\hline
\end{tabular}

(The symbols in Table 5: $A_{1}, \ldots, A_{10}$ : the professional criteria; $b_{j}$; the scores assigned the candidates for each criterion; $u_{j}$ : 'the weights of the criteria' and is constant over all candidates; $s_{j}$ : 'the value of the linguistic quantifier; normalized over all quantifier values' and score for criterion $\mathrm{j} ; \mathrm{s}_{\mathrm{j}}^{2}$ : the representation of most; $\mathrm{w}_{\mathrm{j}}$ : the values of OWA weight; $d_{j}=b j . w j$ )

\section{Conclusion}

In this research we studied how to objectively select the most desirable candidate from the three library manager candidates $(X, Y, Z)$ using fuzzy set theory. We then used the OWA operator to combine all the pieces of information associated with the candidates and the criteria. With the aid of this operator, we respectively calculated the scores for each library manager candidate as $(X=0,610),(Y=0,645)$ and $(Z=0,734)$. So, as the candidate satisfying most of the professional criteria has the highest score, we would choose the candidate ' $Z$ ' as library manager. 


\section{Acknowledgement}

I would like to thank the reviewers for their valuable comments and insights on earlier versions of this article.

\section{References}

ARFI, BADREDINE. 2005. Fuzzy decision making in politics: A linguistic fuzzy-set approach (LFSA). Political Analysis, I3(I): 2356.

BEN-ARIEH, DAVID. 2005. Sensitivity of multi-criteria decision making to linguistic quantifiers and aggregation means. Computers \& Industrial Engineering, 48: 289-309.

BOOKSTEIN, ABRAHAM. 1985. Probability and fuzzy set applications to information retrieval. Annual Review of Information Science and Technology (ARIST). 20:117-15I.

DAE-YOUNG, CHOI. 2003. Enhancing the power of web search engines by means of fuzzy query. Decision Support Systems, 35: $3 \mathrm{I}-44$

DUALIBE, CARLOS. 2003. Design of Analog Fuzzy Logic Controllers in CMOS Technologies: Implementation, Test and Application. USA: Kluwer Academic Publishers.

FILEV, D. \& YAGER, R. 2003. Context dependent information aggregation. Fuzzy Systems 2003, Fuzzy'03 The $12^{\text {th }}$ IEEE International Conference, 25-28 May 2003, I: 672-677.

GARCIA-LAPRESSA, L. 2006. A general class of simple majority decision rules based on linguistic opinions. Information Sciences, 176: 352-365.

HOOD, WILLIAM \& WILSON, C. 2002. Solving problems in library and information science using fuzzy set theory. Library Trends, 50(3): 393-405.

KACPRZYK, J. \& ZADROZYN, S. 2002. A general collective choice rule in group decision making under fuzzy preferences and fuzzy majority: An OWA operator based approach. Proceedings of the 2002 IEEE International Conference Fuzzy Systems, 12 17 May 2002, 2: 1280-I 285.

LEE, J. \& YEUNG, D. \& TSANG, E. 2002. Ordinal fuzzy sets. IEEE Transactions on Fuzzy Systems, I0(6): 767-778.

MAJLENDER, PETER. 2005. OWA operators with maximal Rényi entropy. Fuzzy Sets and Systems, 155(3): 340-360.

MUNAKATA, TORHINORI \& JANI, Y. 1994. Fuzzy systems: An overview. Communications of the ACM, 37(3): 69-76.

PELAEZ, J. \& DONA, J. 2003a. LAMA: A linguistic aggregation of majority additive operator, International Journal Intelligent Systems, 18: 809-820.

PELAEZ, J. \& DONA, J. 2003b. Majority additive-ordered weighted averaging: A new neat ordered operator based on the majority. International Journal Intelligent Systems, 18: 469-48I.

RIBEIRO, R. \& PEREIRA, P. 2003. Generalized mixture operators using weighted functions: A comparative study with WA and OWA. European Journal of Operational Research, 145: 329-342.

ROTH, EMILLE \& MERVIS, CAROLYN. 1983. Fuzzy set theory and class inclusion relations in semantic categories. Journal of Verbal Learning and Verbal, 22: 509-525.

SCHAEFEN, PAUL \& S SCHAEFEN, BARBARA. 1979. Set theory, In: A. Kent, H. Lancour, eds. Encyclopaedia of Library and Information Science, 27: 273-298.

SHENG-LIN, C. \& REAY-CHEN, W. \& SHIH-YUAN, W. 2006. Applying fuzzy linguistic quantifier to select supply chain partners at different phases of product life cycle. International Journal of Production Economics, 100: 348-359.

SMOLIKOVA, RENATA \& WACHOWIAK, M. 2002. Aggregation operators for selection problems. Fuzzy Set and Systems, I3I: 23-34.

TREADWELL, WILLIAM. 1995. Fuzzy set theory movement in the social science. Public Administration Review, 55(I): 91-98.

TURNER, STEPHEN \& O'BRIEN, GREGORY. 1984. A fuzzy set theory approach to periodical binding decision. Journal of the American Society for Information Science, 35(4): 228-234.

XU, Z. 2005. Overview of methods for determining OWA weights. International Journal of Intelligent Systems, 20: 843-865.

$\mathrm{XU}, \mathrm{Z}$. 2004. A method based on linguistic aggregation operators for group decision making with linguistic preference relations. Information Sciences, 166: 19-30.

WANG, YING \& PARKAN, CELIK, 2005. A minimax disparity approach for obtaining OWA operator weights. Information Sciences, 175(I-2): 20-29.

YAGER, R. 2006. An extension of the naïve Bayesian classifier. Information Sciences, 176(5): 577-588.

YAGER, R. 2004a. Constraint satisfaction using soft quantifiers. Intelligent Systems in Accounting Finance and Management, 12: 177-186.

YAGER, R. 2004b. OWA aggregation over a continuous interval argument with applications to decision making. IEEE Transactions on Systems, Man and Cybernetics-Part B: Cybernetics, 34(5): 1952-1969.

YAGER, R. 2002. On the valuation of alternative for decision-making under uncertainty, International Journal of Intelligent Systems, 17: 687-707.

YAGER, R. \& KELMAN, A. 1999. An extension of the analytical hierarchy process using OWA operators. Journal of Intelligent and Fuzzy Systems, 7: 40I-4I7.

YAGER, R. 1999. Nonmonotonic OWA operators. Soft Computing, 187-196.

YAGER, R. 1996. Fuzzy logic in the formulation of decision functions from linguistic specifications. Kybernetes, 25(4): I 19-130.

YAGER, R. 1993. Element selection from a fuzzy subset using the integral. IEEE Transactions on systems, Man and Cybernetics, 23(2): 467-477.

ZADEH, LOTFI. 1965. Fuzzy set. Information and Control, 8: 338-353.

SA Jnl Libs \& Info Sci 2006, 72(3) 